\title{
Positive Helicobacter pylori status is associated with better overall survival for gastric cancer patients: evidence from case- cohort studies
}

\author{
Xuqian Fang ${ }^{1,2, *}$, Kun Liu ${ }^{3, *}$, Jialin $\mathrm{Cai}^{1}$, Fangxiu Luo ${ }^{2}$, Fei Yuan ${ }^{2}$ and Peizhan Chen ${ }^{1}$ \\ ${ }^{1}$ Translational Medicine Research Center, Ruijin Hospital North, Shanghai Jiao Tong University School of Medicine, Shanghai, \\ P. R. China \\ ${ }^{2}$ Department of Pathology, Ruijin Hospital North, Shanghai Jiao Tong University School of Medicine, Shanghai, P. R. China \\ ${ }^{3}$ Department of Surgery, Ruijin Hospital North, Shanghai Jiao Tong University School of Medicine, Shanghai, P. R. China \\ * These authors have contributed equally to this work \\ Correspondence to: Peizhan Chen, email: pzchen@me.com \\ Fei Yuan, email: daphny2014@163.com
}

Keywords: Helicobacter pylori, gastric cancer, overall survival, disease-free survival, meta-analysis

Received: March 27, 2017

Accepted: May 15, 2017

Published: June 28, 2017

Copyright: Fang et al. This is an open-access article distributed under the terms of the Creative Commons Attribution License 3.0 (CC BY 3.0), which permits unrestricted use, distribution, and reproduction in any medium, provided the original author and source are credited.

\section{ABSTRACT}

Helicobacter pylori (H. pylori) infection increases the gastric cancer risk; however, the influences of $\boldsymbol{H}$. pylori infection status on the outcomes for gastric cancer patients have not yet clearly defined. Herein, we systematically assessed the epidemiological studies regarding the associations between the H.pylori infection status at diagnosis and the prognosis for gastric cancer patients with the metaanalysis methods. Thirty-three eligibility studies with 8,199 participants that had determined the H.pylori infection status and the outcomes for gastric cancer patients were identified through searching the PubMed and MEDLINE databases updated to March $1^{\text {st }}, 2017$. The random-effects model suggested that positive $H$. pylori infection was associated with better overall survival with the pooled hazard ratio (HR) was 0.79 [95\% confidence interval $(\mathrm{CI})=0.66-0.93 ; \mathrm{Q}=134.86, \mathrm{df}=32, \mathrm{P}$-heterogeneity < $\left.0.001 ; I^{2}=76.3 \%\right]$ compared to negative patients. The association was found to be more prominent in studies with higher quality, longer following-up time and more sensitive detection methods. An inverse but not statistically significant association between the H.pylori status and the disease-free survival of the patients (pooled HR $=0.84,95 \% \mathrm{CI}=0.61-1.05 ; \mathrm{Q}=30.48, \mathrm{df}=11, \mathrm{P}$-heterogeneity $=0.001 ; I^{2}=63.9 \%$ ) was found, while no significant association was noticed in any subgroup analyses. These results suggested that gastric cancer patients with positive H.pylori infection status at diagnosis have better overall survival compared to negative; however, more studies are warranted to confirm the results and elucidate the underlying mechanisms.

\section{INTRODUCTION}

In spite of a declining incidence rate, gastric cancer remains a major public health issue as it ranks as the third most common cause of cancer deaths worldwide [1]. It was estimated that gastric cancer leads to about 723,100 deaths in 2012 worldwide with more than half of the cases occurred in the Asians $[1,2]$. For gastric cancer patients, surgical resection followed with chemotherapy are still the mainly effective therapy methods, especially for those at earlier stages [3]. It has been reported that clinical characteristics, including age, tumor location, invasion depth, lymph node involvement, and distant metastasis status are important prognosis factors for gastric cancer patients; however, these factors only account for a small proportion of the prognosis heterogeneity among the patients [4]. More prognostic factors are warranted to guide the clinical treatments and identify those patients 
who need more intensive treatments and following-up to improve the outcomes for gastric cancer patients.

H. pylori, a bacteria colonizing in the stomach, is a well-known carcinogen for gastric cancer and H.pylori infection leads to an 7-10 fold increased gastric cancer risk [5]. It was estimated that about $89 \%$ of the new noncardia gastric cancer cases were caused by the bacteria worldwide [6]. In healthy, asymptomatic individuals, $H$. pylori eradication treatment could significantly decrease gastric cancer risk [7]. As a risk factor closely related to gastric cancer development, influences of $H$. pylori infection status on the prognosis of gastric cancer patients have been investigated. Many epidemiological studies have reported that gastric cancer patients with positive $H$. pylori infection status showed a better overall survival (OS) compared to those without infection [8-10]; however, conflicting results were found for other studies that reported no significant association between the $H$. pylori infection status at diagnosis and the outcomes for gastric cancer patients [11-13]. As there the influences of H.pylori infection on the clinical outcomes of gastric cancer patients have not yet well established, we aimed to systematically evaluate the associations between the H.pylori infection status at diagnosis and the prognosis of the gastric cancer patients through meta-analysis of the published epidemiological studies in the current study.

\section{RESULTS}

\section{Eligibility studies identification}

The working flow chart for the eligibility studies identification is presented as Figure 1. From the electronic databases search, a total of 4,032 unique studies that published updated to March 1 ${ }^{\text {st }}, 2017$ were identified with the predefined terms. Through checking the title and abstracts, 3,355 clearly irrelevant studies were excluded. 677 potential studies were further checked with the abstract or the full-length of reports and 644 studies that

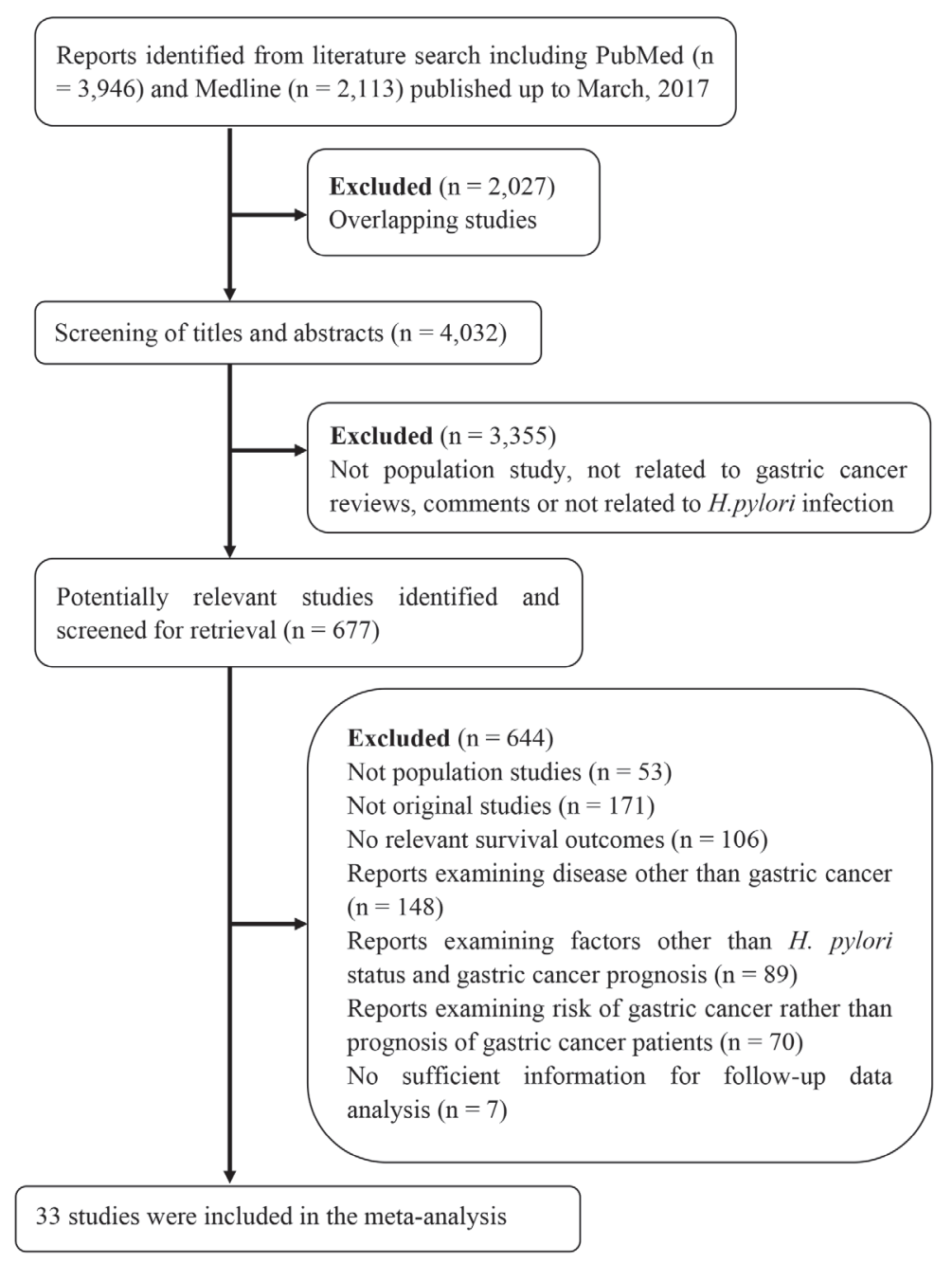

Figure 1: Working flow chart summarizing the studies identification and selection procedure for the meta-analysis studies. 
Table 1: Characteristics of the 33 included studies that have determined the associations between $\boldsymbol{H}$. pylori status (positive $v$ s. negative) and the prognosis for gastric cancer patients.

\begin{tabular}{|c|c|c|c|c|c|c|c|}
\hline Source & $\begin{array}{l}\text { Clinical stage, No. } \\
\text { of patients }\end{array}$ & $\begin{array}{l}\text { Study } \\
\text { country }\end{array}$ & $\begin{array}{l}\text { Median following- } \\
\text { up time (range) }\end{array}$ & $\begin{array}{l}\text { H. pylori detection } \\
\text { method }\end{array}$ & $\begin{array}{l}\text { H. pylori Positive } \\
(\%)\end{array}$ & \begin{tabular}{|l|}
$\mathrm{HR}(95 \% \mathrm{CI})$ \\
for $\mathrm{H}$. pylori \\
positive vs. negative
\end{tabular} & $\begin{array}{l}\text { Quality } \\
\text { score }\end{array}$ \\
\hline Lee et al, 1995 & All stages, 128 & China & 36 months & Serologic analysis & $82(64.10 \%)$ & OS: $0.58(0.35-0.94)^{*}, \mathrm{u}$ & $7 / 10$ \\
\hline Kurtenkov et al, 2003 & $\begin{array}{l}\text { Early stage (I and } \\
\mathrm{II}), 87\end{array}$ & Estonia & NA & Serologic analysis & $58(66.67 \%)$ & OS: $0.37(0.20-0.67)^{*}$, u & $6 / 10$ \\
\hline Meimarakis et al, 2006 & All stages, 166 & Germany & $53.0(1-146)$ months & $\begin{array}{l}\text { Serologic analysis, } \\
\text { histological examination, } \\
\text { Bacterial culture }\end{array}$ & $125(75.30 \%)$ & $\begin{array}{l}\text { OS: } 0.50(0.31-0.82)^{\mathrm{m}} \\
\text { DFS: } 0.46(0.29-0.75)^{\mathrm{m}}\end{array}$ & $10 / 10$ \\
\hline Marrelli et al, 2009 & All stages, 297 & Italy & $62(1-220)$ months & $\begin{array}{l}\text { Serologic analysis, } \\
\text { PCR }\end{array}$ & $256(86.20 \%)$ & OS: $0.40(0.23-0.71)^{\mathrm{m}}$ & $10 / 10$ \\
\hline Qiu et al, 2010 & All stages, 157 & China & \begin{tabular}{rr|}
24.4 & $(0.2-81.8)$ \\
months & \\
\end{tabular} & PCR & $82(52.23 \%)$ & $\begin{array}{l}\text { OS: } 1.09(0.70-1.68)^{*, \mathrm{u}} \\
\text { DFS: } 1.13(0.67-1.92)^{*, \mathrm{u}}\end{array}$ & $6 / 10$ \\
\hline Gan et al, 2011 & All stages, 794 & China & 50 months & Histological examination & $239(30.10 \%)$ & OS: $0.87(0.70-1.08)^{\mathrm{m}}$ & $9 / 10$ \\
\hline Santos et al, 2011 & All stage, 68 & Brazil & $\begin{array}{|ll|}65.6 & (6.7-207.3) \\
\text { months } & \\
\end{array}$ & Histological examination & $34(50 \%)$ & OS: $0.68(0.40-1.16)^{*, u}$ & $7 / 10$ \\
\hline Syrios et al, 2012 & Stage IV, 218 & Greece & NA & Serologic analysis & $76(34.86 \%)$ & OS: $0.83(0.56-1.23)^{\mathrm{u}}$ & $6 / 10$ \\
\hline Kang et al, 2012 & All stage, 274 & Korea & $\begin{array}{ll}144 & (120-184) \\
\text { months } & \\
\end{array}$ & Histological examination & $166(60.58 \%)$ & OS: $0.29(0.20-0.41)^{\mathrm{m}}$ & $9 / 10$ \\
\hline Chen et al , 2012 & All stages, 120 & China & NA & PCR & $21(17.50 \%)$ & OS: $1.54(0.73-3.24)^{\text {и }}$ & $8 / 10$ \\
\hline Chio et al, 2012 & $\begin{array}{ll}\begin{array}{l}\text { Advanced } \\
\text { metastatic, } 61\end{array} & \text { or } \\
\end{array}$ & Korea & NA & Histological examination & $18(29.51 \%)$ & OS: $0.65(0.34-1.23)^{*, u}$ & $6 / 10$ \\
\hline Hur et al, 2012 & All stage, 174 & Korea & NA & $\begin{array}{l}\text { Histological examination, } \\
\text { serologic analysis }\end{array}$ & $111(63.79 \%)$ & $\begin{array}{l}\text { OS: } 0.99(0.45-2.17)^{*, \mathrm{u}} \\
\text { DFS: } 0.57(0.28-1.05)^{*, \mathrm{u}}\end{array}$ & $7 / 10$ \\
\hline Wang, et al 2013 & All stages, 261 & China & \begin{tabular}{|l}
$\begin{array}{l}\text { Range, } \\
\text { months }\end{array}$ \\
\end{tabular} & Histological examination & $188(72.03 \%)$ & $\begin{array}{l}\text { OS: } 0.49(0.27-0.89)^{\mathrm{m}} \\
\text { DFS: } 0.56(0.31-1.00)^{\mathrm{m}} \\
\end{array}$ & $9 / 10$ \\
\hline Li et al, 2013 & All stages, 162 & China & \begin{tabular}{rr|}
35.3 & $(1.7-71.9)$ \\
months & \\
\end{tabular} & Histological examination & $75(46.29 \%)$ & $\begin{array}{l}\text { OS: } 1.71(1.11-2.66)^{\mathrm{m}} \\
\text { DFS: } 1.68(1.05-2.69)^{\mathrm{m}}\end{array}$ & $8 / 10$ \\
\hline Posteraro et al, 2013 & All stages, 110 & Italy & $52.9(1-158)$ months & PCR & $86(78.18 \%)$ & $\begin{array}{l}\text { OS: } 1.15(0.57-2.30)^{\mathrm{u}} \\
\text { DFS: } 0.89(0.47-1.69)^{\mathrm{u}}\end{array}$ & $8 / 10$ \\
\hline Gong et al, 2014 & All stages, 308 & Korea & $70.7 \pm 41.5$ months & Serologic analysis & $259(84.09 \%)$ & OS: $1.06(0.50-2.24)^{u}$ & $8 / 10$ \\
\hline Fang et al, 2014 & $\begin{array}{l}\text { With malignant } \\
\text { ascites, } 347\end{array}$ & China & \begin{tabular}{rr|}
10.4 & $(0.3-60.1)$ \\
months & \\
\end{tabular} & NA & $213(81.30 \%)$ & OS: $1.27(1.06-1.52)^{\mathrm{m}}$ & $7 / 10$ \\
\hline Roberts et al, 2014 & All stages, 79 & West Indies & NA & Histological examination & $15(19.48 \%)$ & OS: $0.46(0.14-1.51)^{\mathrm{u}}$ & $7 / 10$ \\
\hline Ling et al, 2014 & All stages, 300 & China & $28(11-59)$ months & NA & $165(55.00 \%)$ & $\begin{array}{l}\text { OS: } 0.46(0.11-1.93)^{\mathrm{m}} \\
\text { DFS: } 0.57(0.34-0.96)^{\mathrm{m}} \\
\end{array}$ & $7 / 10$ \\
\hline Lian et al, 2014 & All stages, 101 & China & 30.7 (2.7-60) months & Serologic analysis & $64(63.40 \%)$ & $\begin{array}{l}\text { OS: } 0.49(0.27-0.86)^{\mathrm{m}} \\
\text { DFS: } 0.41(0.24-0.85)^{\mathrm{m}} \\
\end{array}$ & $8 / 10$ \\
\hline Kim et al, 2014 & All stages, 533 & Korea & NA & $\begin{array}{|lc|}\text { Serologic } & \text { analysis, } \\
\text { histological examination }\end{array}$ & $509(95.50 \%)$ & $\begin{array}{l}\text { OS: } 0.51(0.07-3.70)^{\mathrm{m}} \\
\text { DFS: } 0.78(0.19-3.21)^{\mathrm{m}}\end{array}$ & $9 / 10$ \\
\hline Shen et al, 2015 & All stages, 136 & China & NA & NA & $126(92.65 \%)$ & OS: $0.70(0.39-1.24)^{\mathrm{u}}$ & $6 / 10$ \\
\hline $\begin{array}{l}\text { Garcia-Gonzalez et al, } \\
2015\end{array}$ & All stages, 558 & Spain & $\begin{array}{l}12.5 \\
\text { months }\end{array}$ & $\begin{array}{l}\begin{array}{l}\text { Urease test, histological } \\
\text { examination, serologic } \\
\text { analysis }\end{array} \\
\end{array}$ & $381(68.28 \%)$ & OS: $1.03(0.84-1.25)^{\mathrm{u}}$ & $8 / 10$ \\
\hline Piao et al, 2015 & All stages, 205 & China & NA & Serologic analysis & $117(57.07 \%)$ & OS: $0.92(0.57-1.50)^{\mathrm{u}}$ & $7 / 10$ \\
\hline Wei et al, 2015 & All stages, 166 & China & NA & NA & $122(73.49 \%)$ & OS: $1.14(0.66-1.98)^{\mathrm{u}}$ & $6 / 10$ \\
\hline Wang et al, 2015 & All stage, 82 & China & NA & $\begin{array}{l}\begin{array}{l}\text { Urease test, } \\
\text { examination, } \\
\text { analysis }\end{array} \\
\text { serological } \\
\end{array}$ & $44(53.66 \%)$ & OS: $0.73(0.12-1.35)^{\mathrm{u}}$ & $8 / 10$ \\
\hline Zhang et al, 2015 & Early stage, 65 & China & 509 (201-1208) days & Serologic analysis & $40(61.53 \%)$ & $\begin{array}{l}\text { OS: } 1.17(0.48-2.85)^{\mathrm{m}} \\
\text { DFS: } 0.91(0.38-2.20)^{\mathrm{m}}\end{array}$ & $8 / 10$ \\
\hline Zhao et al, 2016 & All stages, 600 & China & NA & NA & $475(79.17 \%)$ & OS: $2.52(1.58-4.01)^{\mathrm{u}}$ & $6 / 10$ \\
\hline Zhou et al, 2016 & All stage, 152 & China & 38.1 months & Urease test & $70(46.05 \%)$ & OS: $0.46(0.233-0.909)^{\mathrm{u}}$ & $8 / 10$ \\
\hline Chen et al, 2016 & All stage, 67 & China & NA & NA & $44(65.67 \%)$ & OS: $0.39(0.08-2.00)^{\mathrm{u}}$ & $6 / 10$ \\
\hline Postlewait et al, 2016 & All stage, 559 & China & 49.8 months & NA & $455(81.40 \%)$ & OS: $0.54(0.30-0.99)^{\mathrm{m}}$ & $8 / 10$ \\
\hline Liu et al, 2016 & All stage, 297 & China & Range: $0-95$ months & NA & $208(70.00 \%)$ & $\begin{array}{l}\text { OS: } 1.26(0.74-2.14)^{\mathrm{m}} \\
\text { DFS: } 1.37(0.84-2.23)^{\mathrm{m}}\end{array}$ & $7 / 10$ \\
\hline Tsai et al, 2017 & All stage, 567 & China & NA & $\begin{array}{l}\text { Histological examination, } \\
\text { serologic analysis }\end{array}$ & $435(76.72 \%)$ & $\begin{array}{l}\text { OS: } 0.75(0.58-0.96)^{\mathrm{m}} \\
\text { DFS: } 0.97(0.67-1.40)^{*, \mathrm{u}}\end{array}$ & $9 / 10$ \\
\hline
\end{tabular}

Abbreviations: 95\% CI, 95\% confidence interval; DFS, disease-free survival; H. pylori, Helicobacter pylori; HR, hazard ratio;

$\mathrm{NA}$, not available; OS, overall survival; $\mathrm{u}$, univariate analysis result; $\mathrm{m}$, multivariate analysis result.

*The estimate and its $95 \%$ CI were recalculated based on the provided information in the study. 
did not fully meet the inclusion criteria were excluded from the meta-analysis. 33 studies with a total of 8,199 patients that fully met the inclusion criteria were included in the current meta-analysis studies [8-40].

\section{The study characteristics and quality assessment}

Detailed information of the eligibility studies was provided as Table 1. All the 33 identified studies have determined the associations between the $H$. pylori status at diagnosis and the OS, while only 12 studies determined the disease-free survival (DFS) of gastric cancer patients (Table 1). For the included studies, 26 were performed in Asian countries [10-16, 18-26, 28, 29, 32, 34-40], and 7 in non-Asian countries $[8,9,17,27,30,31,33]$. The sample size of the studies was ranged from 61 to 794 patients, with the H.pylori positive rate of the patients was ranged from $17.5 \%$ to $95.5 \%$. The median following-up for the patients was ranged from 10.4 to 144 months for the included studies. Based on the Newcastle-Ottawa quality assessment scale, the quality scores for the eligibility studies were ranged from 6 to 10 . Seventeen studies with quality score $>7$ were classified as high-quality studies, while sixteen studies with quality score $\leq 7$ were classified as low-quality studies (Supplementary Table 1).

\section{H. pylori status and overall survival of gastric cancer patients}

Under the random-effects model, the pooled hazard ratio (HR) was 0.79 [95\% confidential interval $(95 \%$ CI) $=0.66-0.93$; positive $v s$. negative; Figure 2] of the

\begin{tabular}{|c|c|c|c|c|c|}
\hline \multirow{2}{*}{$\begin{array}{l}\text { Study or Subgroup } \\
\text { Lee, } 1995\end{array}$} & \multicolumn{3}{|c|}{$\begin{array}{c}\text { Hazard Ratio } \\
\text { Rand }\end{array}$} & \multicolumn{2}{|c|}{$\begin{array}{c}\text { Hazard Ratio } \\
\text { IV, Random, 95\% CI }\end{array}$} \\
\hline & $3.5 \%$ & $0.58[0.35,0.95]$ & 1995 & & \\
\hline Kurtenkov, 2003 & $3.1 \%$ & $0.37[0.20,0.68]$ & 2003 & & \\
\hline Meimarakis, 2006 & $3.5 \%$ & $0.50[0.31,0.81]$ & 2006 & & \\
\hline Marrelli, 2009 & $3.2 \%$ & $0.40[0.23,0.70]$ & 2009 & & \\
\hline Qiu, 2010 & $3.7 \%$ & $1.09[0.70,1.69]$ & 2010 & - & $t_{0}$ \\
\hline Santos, 2011 & $3.3 \%$ & $0.68[0.40,1.16]$ & 2011 & & + \\
\hline Gan, 2011 & $4.5 \%$ & $0.87[0.70,1.08]$ & 2011 & & \\
\hline Kang, 2012 & $4.0 \%$ & $0.29[0.20,0.42]$ & 2012 & & \\
\hline Syrios, 2012 & $3.9 \%$ & $0.83[0.56,1.23]$ & 2012 & & - \\
\hline Chen, 2012 & $2.6 \%$ & $1.54[0.73,3.24]$ & 2012 & & \\
\hline Hur, 2012 & $2.4 \%$ & $0.99[0.45,2.17]$ & 2012 & & \\
\hline Chio, 2012 & $2.9 \%$ & $0.65[0.34,1.24]$ & 2012 & & - \\
\hline Wang, 2013 & $3.1 \%$ & $0.49[0.27,0.89]$ & 2013 & & \\
\hline Posteraro, 2013 & $2.7 \%$ & $1.15[0.57,2.31]$ & 2013 & & \\
\hline Li, 2013 & $3.7 \%$ & $1.71[1.10,2.65]$ & 2013 & & \\
\hline Roberts, 2014 & $1.5 \%$ & $0.46[0.14,1.51]$ & 2014 & & - \\
\hline Kim, 2014 & $0.7 \%$ & $0.51[0.07,3.71]$ & 2014 & & \\
\hline Fang, 2014 & $4.6 \%$ & $1.27[1.06,1.52]$ & 2014 & & - \\
\hline Gong, 2014 & $2.6 \%$ & $1.06[0.50,2.24]$ & 2014 & & \\
\hline Ling, 2014 & $1.1 \%$ & $0.46[0.11,1.93]$ & 2014 & & \\
\hline Lian, 2014 & $3.2 \%$ & $0.49[0.27,0.87]$ & 2014 & & \\
\hline Wei, 2015 & $3.3 \%$ & $1.14[0.66,1.97]$ & 2015 & & \\
\hline Piao, 2015 & $3.5 \%$ & $0.92[0.57,1.49]$ & 2015 & & 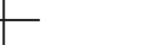 \\
\hline Garcia-Gonzalez, 2015 & $4.6 \%$ & $1.03[0.84,1.26]$ & 2015 & & $t$ \\
\hline Wang, 2015 & $1.5 \%$ & $0.73[0.22,2.45]$ & 2015 & & \\
\hline Zhang, 2015 & $2.1 \%$ & $1.17[0.48,2.85]$ & 2015 & & \\
\hline Shen, 2015 & $3.2 \%$ & $0.70[0.39,1.25]$ & 2015 & & - \\
\hline Chen, 2016 & $0.9 \%$ & $0.39[0.08,1.95]$ & 2016 & & \\
\hline Postlewait, 2016 & $3.1 \%$ & $0.54[0.30,0.98]$ & 2016 & & \\
\hline Liu, 2016 & $3.3 \%$ & $1.26[0.74,2.14]$ & 2016 & & \\
\hline Zhou, 2016 & $2.8 \%$ & $0.46[0.23,0.91]$ & 2016 & & \\
\hline Zhao, 2016 & $3.6 \%$ & $2.52[1.58,4.01]$ & 2016 & & \\
\hline Tsai, 2017 & $4.4 \%$ & $0.75[0.58,0.96]$ & 2017 & - & \\
\hline Total $(95 \% \mathrm{CI})$ & $100.0 \%$ & $0.79[0.66,0.93]$ & & $>$ & \\
\hline $\begin{array}{l}\text { Heterogeneity: } \mathrm{Tau}^{2}=0 \\
\text { Test for overall effect: } \mathrm{Z}\end{array}$ & $\begin{array}{l}6 ; \mathrm{Chi}^{2}= \\
2.72(\mathrm{P}=\end{array}$ & $\begin{array}{l}=134.69, \mathrm{df}=32(\mathrm{P}< \\
=0.006)\end{array}$ & $0.00001) ;\left.\right|^{2}=76 \%$ & $\begin{array}{l}\qquad \begin{array}{l}1 \\
0.050 .2 \\
\text { H. pylori Positive }\end{array} \\
\end{array}$ & H. pylori \\
\hline
\end{tabular}

Figure 2: Forest plot for the association between $H$. pylori status (positive vs. negative) at diagnosis and overall survival of gastric cancer patients. 
Table 2: Stratification analyses for the association between $H$. pylori infection (positive vs. negative) status at diagnosis and the overall survival of gastric cancer patients.

\begin{tabular}{|c|c|c|c|c|c|c|c|}
\hline Stratification factor & \begin{tabular}{|l|} 
No. of \\
Studies/ \\
Patients
\end{tabular} & \begin{tabular}{|l|} 
Random-effects \\
model HR \\
$(95 \% \mathrm{CI}) *$
\end{tabular} & Q/df & P-heterogeneity & $\mathrm{I}^{2}$ & $\begin{array}{l}\text { Egger's } \\
\text { test }\end{array}$ & $\begin{array}{l}\text { Begg's } \\
\text { test }\end{array}$ \\
\hline Overall survival & $33 / 8,199$ & $0.79(0.66-0.93)$ & $134.86 / 32$ & $<0.001$ & $76.3 \%$ & 0.086 & 0.337 \\
\hline \multicolumn{8}{|l|}{ Disease stage } \\
\hline Early stage & $2 / 152$ & $0.63(0.20-1.93)$ & $4.39 / 1$ & 0.036 & $77.2 \%$ & NA & NA \\
\hline Advanced stage & $3 / 317$ & $0.76(0.55-1.05)$ & $0.90 / 2$ & 0.638 & $0.0 \%$ & 0.191 & 0.117 \\
\hline All stage & $29 / 7,768$ & $0.80(0.66-0.97)$ & $125.56 / 28$ & $<0.001$ & $77.7 \%$ & 0.126 & 0.294 \\
\hline \multicolumn{8}{|l|}{ Region } \\
\hline Asia & $26 / 6,703$ & $0.81(0.65-1.00)$ & $117.04 / 25$ & $<0.001$ & $78.6 \%$ & 0.235 & 0.343 \\
\hline Non-Asia & $7 / 1,496$ & $0.71(0.52-0.97)$ & $17.45 / 6$ & 0.008 & $65.6 \%$ & 0.099 & 0.293 \\
\hline \multicolumn{8}{|l|}{ Statistical methodology } \\
\hline Multivariate analysis & $14 / 4,723$ & $0.70(0.52-0.94)$ & $88.27 / 13$ & $<0.001$ & $85.3 \%$ & 0.157 & 0.870 \\
\hline Univariate analysis & $23 / 4,658$ & $0.86(0.71-1.04)$ & $59.13 / 22$ & $<0.001$ & $62.8 \%$ & 0.265 & 0.476 \\
\hline \multicolumn{8}{|l|}{ Study quality } \\
\hline Higher (Quality score > 7) & $17 / 5,109$ & $0.71(0.56-0.91)$ & $77.35 / 16$ & $<0.001$ & $78.2 \%$ & 0.414 & 0.680 \\
\hline Lower (Quality score $\leq 7$ ) & $16 / 3,090$ & $0.88(0.69-1.11)$ & $48.10 / 15$ & $<0.001$ & $68.8 \%$ & 0.028 & 0.150 \\
\hline \multicolumn{8}{|l|}{ Median following-up time } \\
\hline$>36$ months & $12 / 3,279$ & $0.64(0.47-0.87)$ & $55.56 / 11$ & $<0.001$ & $80.2 \%$ & 0.577 & 0.784 \\
\hline$\leq 36$ months & $21 / 4,920$ & $0.92(0.76-1.11)$ & $54.65 / 20$ & $<0.001$ & $63.4 \%$ & 0.122 & 0.205 \\
\hline \multicolumn{8}{|l|}{ Sample size } \\
\hline$>200$ & $15 / 6,118$ & $0.80(0.62-1.04)$ & $92.7 / 14$ & $<0.001$ & $84.9 \%$ & 0.261 & 0.299 \\
\hline$\leq 200$ & $18 / 2,081$ & $0.77(0.61-0.97)$ & $39.41 / 17$ & 0.002 & $56.9 \%$ & 0.444 & 0.791 \\
\hline \multicolumn{8}{|l|}{ H. pylori detection method } \\
\hline Serologic analysis & $7 / 1,112$ & $0.70(0.52-0.93)$ & $10.69 / 6$ & 0.099 & $43.9 \%$ & 0.941 & 0.881 \\
\hline Histological examination & $8 / 1,873$ & $0.69(0.44-1.07)$ & $45.55 / 7$ & $<0.001$ & $84.6 \%$ & 0.742 & 0.621 \\
\hline PCR & $3 / 387$ & $1.18(0.85-1.65)$ & $0.62 / 2$ & 0.733 & $0.0 \%$ & 0.433 & 0.117 \\
\hline Two or more methods & $6 / 2,203$ & $0.68(0.48-0.95)$ & $16.00 / 5$ & 0.007 & $68.7 \%$ & 0.183 & 0.573 \\
\hline NA or other & $9 / 2,624$ & $0.94(0.65-1.35)$ & $31.42 / 8$ & $<0.001$ & $74.5 \%$ & \begin{tabular}{|l|l|}
0.148 \\
\end{tabular} & 0.022 \\
\hline \multicolumn{8}{|c|}{\begin{tabular}{l|l}
$\begin{array}{l}\text { H.pylori positive percent in } \\
\text { gastric cancer patients }\end{array}$ & \\
\end{tabular}} \\
\hline$>64.0 \%$ & $17 / 5,187$ & $0.80(0.63-1.01)$ & 72.41 & $<0.001$ & $77.9 \%$ & 0.081 & 0.249 \\
\hline$\leq 64.0 \%$ & $16 / 3,012$ & $0.77(0.59-1.00)$ & $56.33 / 15$ & $<0.001$ & $73.4 \%$ & 0.860 & 0.418 \\
\hline
\end{tabular}

Abbreviations: 95\% CI, 95\% confidence interval; HR, hazard ratio; H. pylori, Helicobacter pylori; NA, not available; PCR, Polymerase chain reaction.

$* \mathrm{HR}=1$ for negative $H$. pylori status;

33 eligibility studies that determined the influences of H.pylori infection status and OS of gastric cancer patients, suggesting that gastric cancer patients with positive $H$. pylori status was associated with better OS in relative to negative. Significant heterogeneity between the studies was found $(\mathrm{Q}=134.86$, df $=32$, P-heterogeneity < $\left.0.001 ; I^{2}=76.3 \%\right)$. The sensitivity studies showed that no individual study significantly affected the overall estimate of the meta-analysis. We applied the Baujat plot to identify those studies that largely contributed to the heterogeneity between the studies, and found that three studies performed by Kang et al. [20], Fang et al. [11], and Zhao et al. [38] caused significant heterogeneity between the studies (Supplementary Figure 1). When these three studies were excluded, we still found that gastric cancer patients with positive H.pylori status at diagnosis were associated with better OS compared to those of negative status (pooled HR $=0.78,95 \% \mathrm{CI}=0.67-0.90$ ). A significant reduction of the heterogeneity between the studies was noticed for the 30 included studies (Q $=60.52, \mathrm{df}=29$, P-heterogeneity $\left.=0.005 ; I^{2}=52.1 \%\right)$. No significant publication bias was noticed as suggested by the funnel plot (Egger's test, $P=0.086$ and Begg's test, $P=0.337$; Figure 3 ). The cumulative meta-analysis suggested that the pooled estimate was chronologically stable (Supplementary Figure 2). 
Table 3: Stratification analyses for the association between the $H$. pylori infection (positive vs. negative) status at diagnosis and the disease-free of survival of gastric cancer patients.

\begin{tabular}{|c|c|c|c|c|c|c|c|}
\hline Stratification factor & $\begin{array}{ll}\text { No. } & \text { of } \\
\text { Studies/ } \\
\text { Patients }\end{array}$ & $\begin{array}{l}\text { Random-effects } \\
\text { model HR } \\
(95 \% C I) *\end{array}$ & $Q / d f$ & $P$-heterogeneity & $I^{2}$ & $\begin{array}{l}\text { Egger's } \\
\text { test }\end{array}$ & Begg's test \\
\hline Overall & $12 / 2,893$ & $0.80(0.61-1.05)$ & $30.48 / 11$ & 0.001 & $63.9 \%$ & 0.454 & 0.493 \\
\hline \multicolumn{8}{|l|}{ Region } \\
\hline Asia & $10 / 2617$ & $0.84(0.63-1.14)$ & $23.79 / 9$ & 0.005 & $62.2 \%$ & 0.327 & 0.245 \\
\hline Non-Asia & $2 / 276$ & $0.62(0.33-1.17)$ & $2.63 / 1$ & 0.105 & $62.0 \%$ & NA & NA \\
\hline \multicolumn{8}{|l|}{$\begin{array}{l}\text { Statistical } \\
\text { methodology }\end{array}$} \\
\hline Univariate analysis & $7 / 1,631$ & $0.96(0.72-1.28)$ & $12.40 / 6$ & 0.054 & $51.6 \%$ & 0.388 & 0.652 \\
\hline Multivariate analysis & $8 / 1,885$ & $0.75(0.49-1.14)$ & $26.81 / 7$ & 0.004 & $73.9 \%$ & 0.720 & 0.805 \\
\hline \multicolumn{8}{|l|}{ Study quality } \\
\hline $\begin{array}{l}\text { Higher (Quality score } \\
>7 \text { ) }\end{array}$ & $8 / 1,965$ & $0.76(0.53-1.11)$ & $21.73 / 7$ & 0.003 & $67.8 \%$ & 0.624 & 0.621 \\
\hline $\begin{array}{l}\text { Lower (Quality score } \\
\leq 7)\end{array}$ & $4 / 928$ & $0.86(0.55-1.36)$ & $8.37 / 3$ & 0.039 & $64.1 \%$ & 0.391 & 0.497 \\
\hline \multicolumn{8}{|l|}{$\begin{array}{l}\text { Median following-up } \\
\text { time }\end{array}$} \\
\hline$>36$ months & $4 / 699$ & $0.79(0.42-1.48)$ & $16.30 / 3$ & 0.001 & $81.6 \%$ & 0.825 & 1.000 \\
\hline$\leq 36$ months & $8 / 2,194$ & $0.81(0.60-1.09)$ & $14.11 / 7$ & 0.049 & $50.4 \%$ & 0.450 & 0.458 \\
\hline \multicolumn{8}{|l|}{$\begin{array}{l}\text { H. pylori detection } \\
\text { method }\end{array}$} \\
\hline PCR & $2 / 267$ & $1.03(0.68-1.54)$ & $0.32 / 1$ & 0.572 & $0.0 \%$ & NA & NA \\
\hline $\begin{array}{l}\text { Histological } \\
\text { examination }\end{array}$ & $3 / 597$ & $0.83(0.38-1.80)$ & $11.06 / 2$ & 0.004 & $81.9 \%$ & 0.233 & 0.602 \\
\hline Serologic analysis & $2 / 166$ & $0.57(0.27-1.24)$ & $2.09 / 1$ & 0.149 & $52.1 \%$ & NA & NA \\
\hline NA & $2 / 597$ & $0.89(0.38-2.10)$ & $5.82 / 1$ & 0.016 & $82.8 \%$ & NA & NA \\
\hline Two or more & $3 / 1,266$ & $0.69(0.38-1.25)$ & $5.92 / 2$ & 0.052 & $66.2 \%$ & 0.864 & 0.602 \\
\hline \multicolumn{8}{|l|}{ Sample size } \\
\hline$>200$ & $5 / 1,958$ & $0.83(0.58-1.19)$ & $8.40 / 4$ & 0.078 & $52.4 \%$ & 0.638 & 0.624 \\
\hline$\leq 200$ & $7 / 935$ & $0.78(0.51-1.19)$ & $21.91 / 6$ & 0.001 & $72.6 \%$ & 0.642 & 0.652 \\
\hline \multicolumn{8}{|l|}{$\begin{array}{l}\text { H.pylori in positive } \\
\text { percent in gastric } \\
\text { cancer patients }\end{array}$} \\
\hline$>64.0 \%$ & $6 / 1,934$ & $0.80(0.55-1.14)$ & $12.43 / 5$ & 0.029 & $59.8 \%$ & 0.774 & 0.851 \\
\hline$\leq 64.0 \%$ & $6 / 959$ & $0.80(0.50-1.26)$ & $18.00 / 5$ & 0.003 & $72.2 \%$ & 0.375 & 0.573 \\
\hline
\end{tabular}

Abbreviations: 95\% CI, 95\% confidence interval; H. pylori, Helicobacter pylori; HR, hazard ratio; NA, not applicable; PCR, polymerase chain reaction.

$* \mathrm{HR}=1$ for negative $H$. pylori status.

To explore the potential heterogeneity between the studies, the subgroup and the meta-regression analyses were performed to identify the study level characteristics that might significant influence the pooled estimate. In the subgroup study, we found the association was more prominent in patients from non-Asian countries (pooled $\mathrm{HR}=0.71,95 \% \mathrm{CI}=0.52-0.97)$ in relative to those from Asian countries (pooled HR $=0.81,95 \% \mathrm{CI}=0.65-1.00$; Table 2). Studies with higher quality (pooled $\mathrm{HR}=0.71$, $95 \% \mathrm{CI}=0.52-0.97$ ), longer follow-up time (pooled $\mathrm{HR}=$ $0.64,95 \% \mathrm{CI}=0.47-0.87)$ and relative smaller sample size (pooled $\mathrm{HR}=0.77,95 \% \mathrm{CI}=0.61-0.97$ ) showed more prominent associations between $H$. pylori status and the OS of gastric cancer patients compared to studies of lower quality, shorter follow-up time or relatively larger sample size (Table 2). In the stratification analyses of the $H$. pylori detection method, a significant association was found for those studies conducted with two or more $H$. pylori detection methods (pooled $\mathrm{HR}=0.68,95 \% \mathrm{CI}=0.48$ 0.95 ) or with serologic analysis (pooled $\mathrm{HR}=0.70,95 \%$ $\mathrm{CI}=0.52-0.93$ ); however, no significant association was found in those studies that only performed the histological examination or PCR detection tests (Table 2). The prognosis of gastric cancer patients might be influenced by 
the clinical stage. The pooled estimate from 14 studies with multivariate adjustment for the cofounders (including age, sex, tumor location, disease stage, and adjuvant treatment etc.) suggested that positive $H$. pylori was associated with improved OS of gastric cancer patients (pooled HR $=0.70,95 \% \mathrm{CI}=0.52-0.94)$, whereas pooled estimate for 23 studies of univariate analysis showed a negative but non-statistically significant association between the H.pylori infection status and OS (pooled HR $=0.86,95 \%$ $\mathrm{CI}=0.71-1.04$; Table 2). However, the meta-regression studies suggested the pooled estimates between the groups were not significantly different (data not shown). For all the stratified studies, significant heterogeneity between the studies was noticed and no significant publication bias was evident as suggested by the funnel plots in together with the Egger's test or Begg's test (Table 2). The sensitivity analyses suggested that none individual study significantly influenced the pooled estimate in any subgroup studies.

\section{H. pylori status and disease-free survival of gastric cancer patients}

Twelve studies with a total of 2,893 gastric cancer patients have determined the associations between the H. pylori status and the DFS for gastric cancer patients. The pooled estimate suggested that patients with positive H. pylori status showed an improved but not statistically significant better DFS (pooled HR $=0.80,95 \% \mathrm{CI}=$ 0.61-1.05; Figure 4) compared to those without $H$. pylori infection. Significant heterogeneity between the studies was evident $\left(\mathrm{Q}=30.48, \mathrm{df}=11, P=0.001, I^{2}\right.$ $=63.9 \%$ ). None of the individual studies significantly affect the pooled estimate as suggested by the sensitivity studies. With the Baujat plot, we noticed that four studies performed by Meimarakis et al. [9], Li et al. [12], Lian et al. [24] and Liu et al. [25] largely contributed to the overall heterogeneity between the studies (Supplementary Figure 3). The pooled estimate for the remained eight studies was $0.80(95 \% \mathrm{CI}=0.65-0.98)$ and no significant heterogeneity between the studies was noticed $(\mathrm{Q}=6.97$, df $\left.=7, P=0.432 ; I^{2}=0.0 \%\right)$. The funnel plot suggested that no significant publication was noticed for the included studies (Figure 5; Egger's test, $P=0.454$ and Begg's test, $P=0.493)$. The cumulative meta-analysis suggested that the pooled estimate was chronically stable for the association between the H.pylori status and the DFS of gastric cancer patients (Supplementary Figure 4).

In the stratification studies, we found no significant association between the H.pylori infection status and the DFS for gastric cancer patients in any subgroup study stratified by the study region, H.pylori infection method, sample size, H.pylori positive percent, study quality, following-up time or whether the estimate was adjusted by covariates (Table 3). The meta-regression also suggested that none of these study-level characteristics significantly influenced the pooled estimate (data not shown). For all the subgroup studies, no significant publication bias was identified and the sensitivity studies suggested that none of the individual study significantly affected the pooled estimates (Table 3 ).

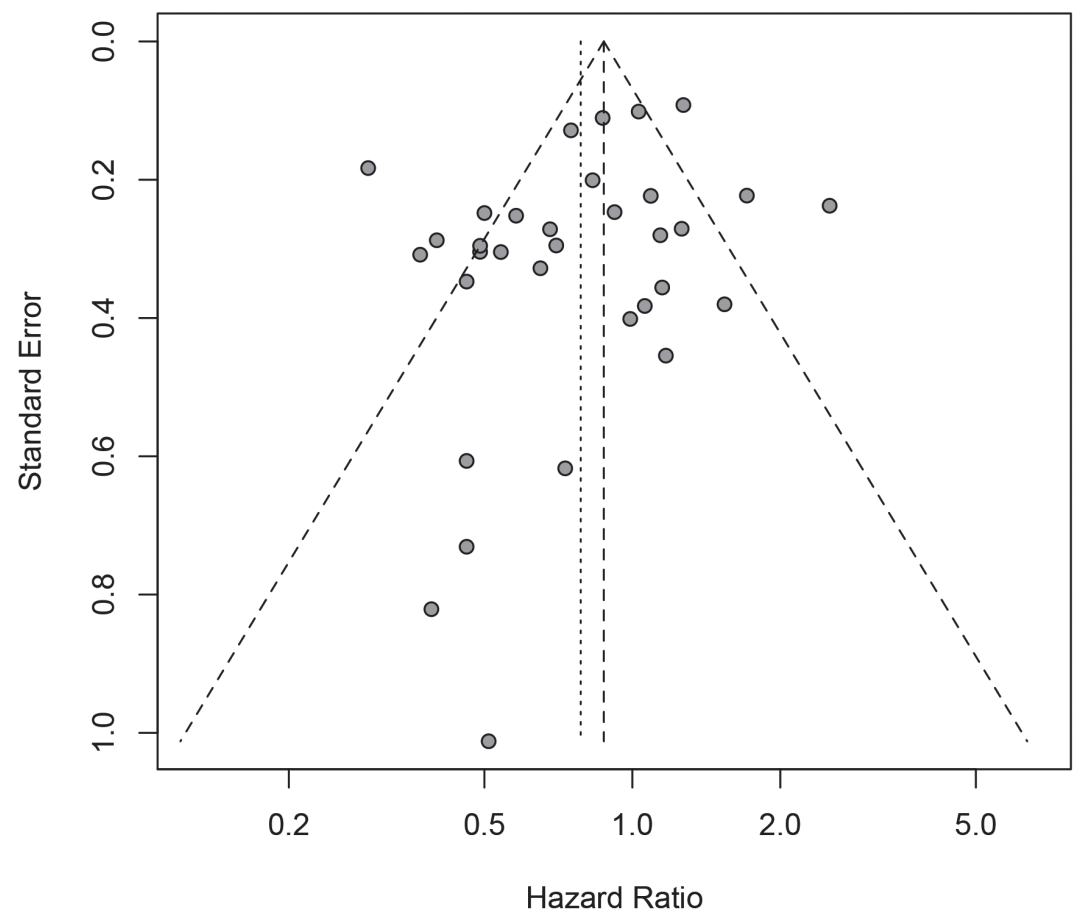

Figure 3: Funnel plot for the estimated risk between $H$.pylori infection status (positive vs. negative) at diagnosis and the overall survival of gastric cancer patients. 


\section{DISCUSSION}

It has been more than 30 years since the discovery of H. pylori infections in the stomach of human [41]. The International Agency for Research on Cancer (IARC) has classified $H$. pylori as a type 1 carcinogen for gastric cancer [42]. H. pylori infection leads to the chronic gastritis, peptic ulcers of the stomach, and a chronic inflammatory process that may increase the risk of metaplastic epithelium and subsequent gastric cancer [43]. A previous published meta-analysis for randomized controlled trials confirmed that, $H$. pylori eradication reduced the risk for gastric cancer in those healthy and asymptomatic individuals; however, for those with preneoplastic conditions, $H$. pylori eradication have limited effects on the reduction of gastric cancer risk [7]. Thus, H. pylori infection is a risk factor for development of gastric cancer, and H.pylori eradication has preventive effects in the gastric cancer development. In the current study, through systematically evaluating the epidemiological studies, we reported that gastric cancer patients with positive $H$. pylori showed better OS compared to those without the infection at the time of diagnosis. As the H.pylori infection could be easily detected before the resection treatment, it could be served as an independent prognostic prediction biomarker for OS in gastric cancer patients. Moreover, the detection of H.pylori status could have substantial effects on disease outcomes as the results suggested that gastric cancer patients with negative $H$. pylori infection at diagnosis might need more stringent treatments.

Owing to the long evolutionary cohabitation of $H$. pylori with humankind, it has been suggested that this bacterium might confer some benefits to individuals. For example, $H$. pylori is a protective factor for symptom severity, symptom evolution and treatment response in gastroesophageal reflux disease [44]. H. pylori infection also protect infected individuals from development of atopic diseases through the modulation of the activities for Treg cells [45]. For gastric cancer, our current study suggested that gastric cancer patients with positive H.pylori have favorable outcomes through integrating the epidemiological studies. This seems paradoxical but still have biological underlying mechanisms. First, the immunological consequences of $H$. pylori infected might contribute to the favorable outcomes for gastric cancer patients. H.pylori infection-induced mucosal inflammation is Th1 mediated [46], and tumor infiltration by Th1 cells is associated with improved prognosis of patients [47]. H.pylori-infected macrophages also induce Th17 cell differentiation and increased Th17 cells have been reported to predict better survival in gastric cancer patients [48]. Persistent $H$. pylori infection might also exert protective effects by the secretion of $H$. pylori neutrophilactivating protein (HP-NAP). HP-NAP is a major virulence factor and a powerful inducer for inflammatory reaction and Th1-polarized immune response $[49,50]$. Recent studies indicated that HP-NAP inhibits the growth of bladder cancer through activating the cytotoxic Th1 responses [51]. Moreover, expression of secreted HP-NAP by adenovirus has been shown to enhance the antitumor activity of these viruses in the treatment of metastatic breast cancer and neuroendocrine tumors, respectively [ 52 , 53]. Second, several studies have suggested that H.pylori infection might increase the microsatellite instability (MSI) [54, 55], which was reported to be associated with better outcomes for gastric cancer patients [56]. Third, the signal regulated by the H.pylori in the gastric cells might contribute to the outcomes for gastric cancer patients, Zhou et al. reported that $H$. pylori reduced the microRNA-141 expression, which increased the expression of its target

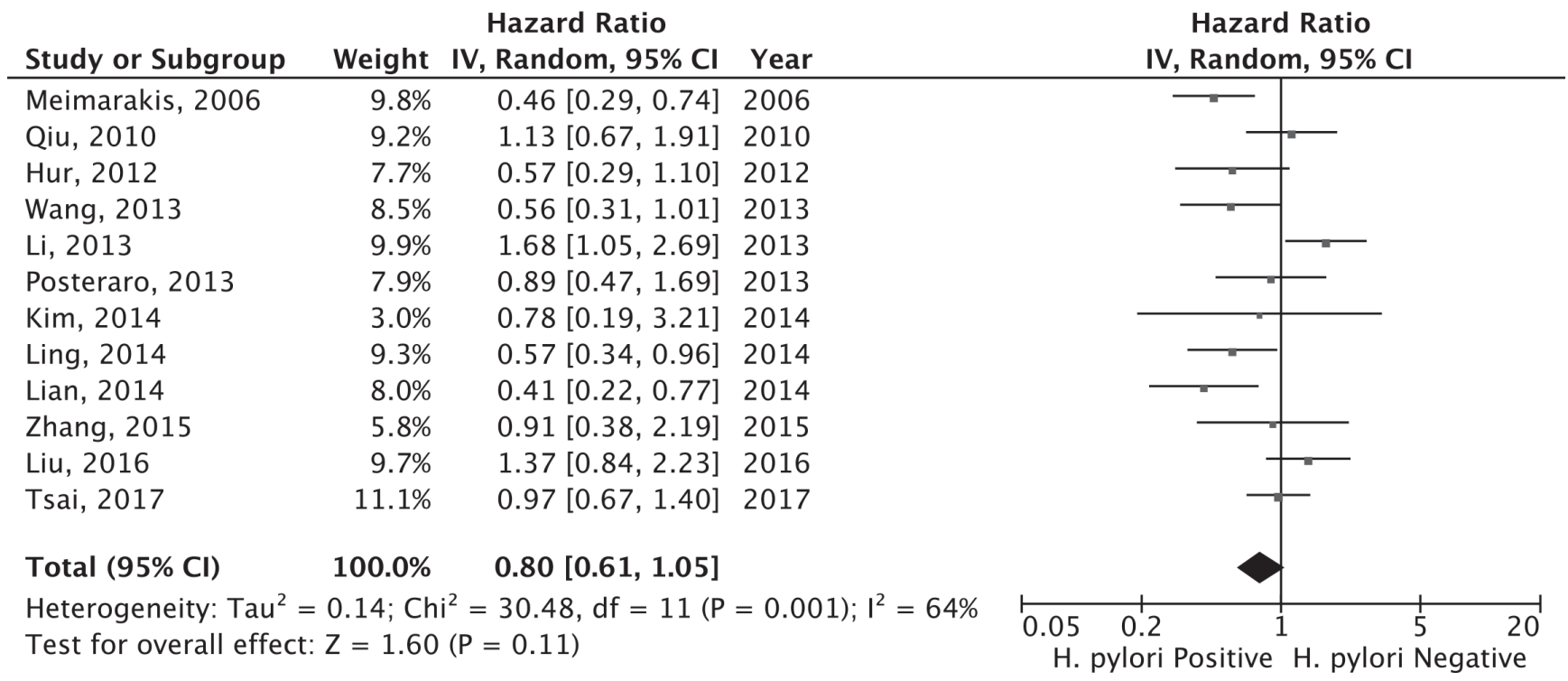

Figure 4: Forest plot for $\boldsymbol{H}$. pylori status (positive vs. negative) and disease-free survival for gastric cancer patients. 
gene KEAP1 and thus enhanced the sensitivity of the gastric cancer cells to cisplatin [57]. Choi et al. reported that H.pylori positive patients with advanced or metastatic gastric cancer had a better response to 5-FU and cisplatin adjunct chemotherapy and an improved overall prognosis compared with patients without H.pylori infection [16]. At last, clinical studies indicated that patients with negative H.pylori infection was correlated with the advanced stage of gastric cancer patients [58]. Moreover, several studies also suggested that gastric cancer with negative H.pylori infection status were usually found in the proximal (cardia or fundus) compared to the distal (antrum or corpus) for H.pylori positive status [9, 28, 29], and it has been reported that proximal location was correlated with poorer OS for gastric cancer patients compared to distal location $[59,60]$. All these might contribute to the improved OS of H. pylori positive gastric cancer patients; however, more studies are warranted to fully elucidate the protective roles of the H.pylori in the progression of gastric cancer patients and the underlying mechanisms.

Compared to a previous meta-analysis study performed by Wang et al. [61], the current study provided stronger evidence for the association between H.pylori infection status at diagnosis and the OS for gastric cancer patients with larger sample size. In the subgroup analyses, we found the association magnitude between the H.pylori infection status and the OS was different between the Asian and non-Asian populations (Table
2). We proposed that the baseline characteristics of the populations including genetic, dietary habits, disease treatment methods of gastric cancer patients and the detection methods for H.pylori infection status might influence the association. In addition, it has been widely known that the H.pylori strains between the Asian and non-Asian populations were different, especially for the virulence protein cagA of H.pylori [62]. cagA of the Asian populations infected H.pylori strains leads to more severe immune responses and epithelial cytoskeletal changes in gastric epithelial cells [63]. These might contribute to the different associations between H.pylori infection status and outcomes of gastric cancer patients in the Asian and non-Asian population. In the stratification analysis of the H.pylori detection methods, a significant association was noticed for those studies conducted with the serologic analysis method or with two more detection methods but not for those studies only single method including histological or PCR examination. It has been reported that the colonization might be not suitable for H.pylori in the gastric cancer tissues as the $\mathrm{pH}$ might be raised due to the alkalization of the cells in the gastric cancer development [19]. The histological and PCR examination was usually conducted in the gastric cancer tissues instead of the other sites for H.pylori colonization, which might lead to false negative results for H.pylori infection tests. Therefore, two or more detection methods would be necessary to accurately determine the H.pylori status for gastric cancer

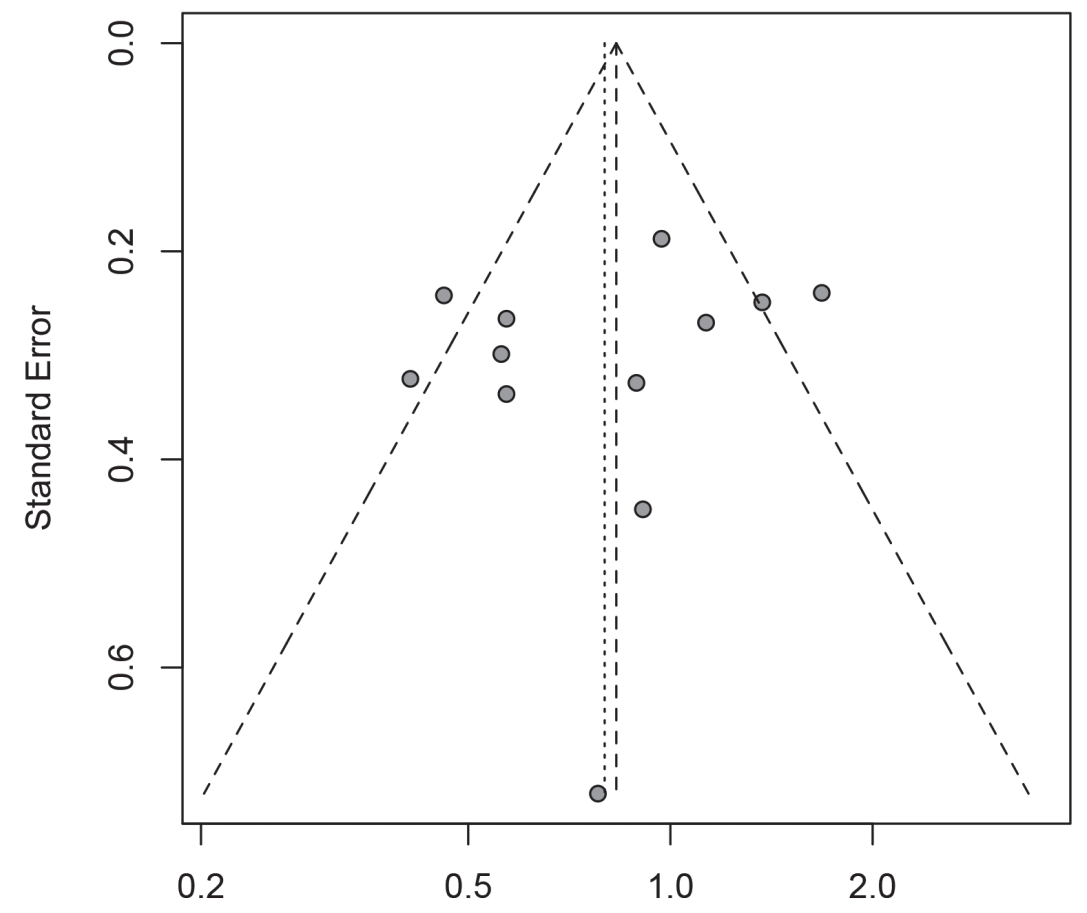

Hazard Ratio

Figure 5: Funnel plot for the estimated risk between $H$.pylori infection status (positive vs. negative) at diagnosis and the disease-free survival of gastric cancer patients. 
patients in order to predict the outcomes of gastric cancer patients according to the H.pylori status. A negative but non-statistically significant association between the H.pylori infection status at diagnosis and the DFS for gastric cancer patients was noticed in the meta-analysis of 12 eligibility studies, suggesting more studies with larger sample size are warranted to elucidate the influences of H.pylori on the disease progression of the gastric cancer patients.

We acknowledged there were several limitations for the current meta-analysis should to be stated. First, there was significant heterogeneity between the studies, which may be caused by study-specific characteristics. Stratified analyses only partially reduced the heterogeneity between the studies as the subgroup studies also found significant heterogeneity between the studies. We also applied the Baujat plot to identify those studies that largely contribute to the heterogeneity between the studies, and found the association between H.pylori infection and OS was still significant after excluding those studies, suggesting that the results were robust. Secondly, the strains of $H$. pylori should be determined for infected gastric cancer patients, as the bacteria strains between the non-Asian populations and the Asian populations are different, and the host immune responses for $H$. pylori infection between the strains depends on the cag pathogenicity island of the bacteria [64]. Strain-specific effects of $H$. pylori on gastric cancer prognosis should be determined. At last, the pooled estimates were varied according to the H.pylori detection methods. Studies performed with the serologic analysis could not exclude the possibility that a previous H.pylori infection history but not the positive status at diagnosis was associated with the OS of gastric cancer patients. Studies with combined sensitive H.pylori detection methods are warranted to further address the related questions in future.

In conclusion, the current study reported that gastric cancer patients with $H$. pylori infections have better outcomes in relative to those without infection at diagnosis. Unbiased studies with larger sample sizes are warranted to validate the conclusions, and the underlying mechanisms need to be explored with more studies.

\section{MATERIALS AND METHODS}

\section{Literature search}

Eligible studies were identified by searching the PubMed and MEDLINE databases published up to March $1^{\text {st }}, 2017$ following the Preferred Reporting Items for Systematic Reviews and Meta-Analyses (PRISMA) guidelines. The following terms (1) "gastric" OR "stomach" OR "cardia"; (2) "cancer" OR "carcinoma" OR "neoplasia” OR "adenocarcinoma"; (3) "Helicobacter pylori" OR “H. pylori”; (4) "outcome" OR "prognosis" OR "survival" were used to identify studies that evaluated the association between $H$. pylori infection status and outcomes for gastric cancer patients. In addition, we also checked the references of the identified eligibility studies to search for potential missing studies. Only those studies published in English were included in the current study. The EndNote software (version X7.4, Thomson Reuters) was applied to detect the repeated reports in the two databases and retrieve the title and abstract of the reports.

\section{Eligibility study criteria}

Standardized inclusion criteria were applied to the retrieved reports. First, the study should be of case-cohort design and evaluated the H.pylori status at the time of diagnosis (positive or negative); Second, the outcomes for the gastric cancer patients including the OS, cancerspecific mortality, relapse-free survival or DFS should be compared between the groups of H.pylori status (positive vs. negative); Third, each study should classify the $H$. pylori status for the gastric cancer patients at diagnosis and provide the correlating estimated HR and it corresponding 95\% CI for the outcomes under the Cox proportional hazard model (univariate or multiple variate analyses) or provided a Kaplan-Meier plot that could be used to calculate the HR and its $95 \%$ CI estimate for patients. We excluded those studies if they: 1) with overlapping participants with other studies but of relative smaller sample size; 2) did not provide sufficient information to calculate the risk estimate for H.pylori positive vs. negative patients; 3) were not published as full reports (e.g. conference abstracts).

\section{Data extraction}

The following data were extracted from each study: last name of the first author, year of publication, study country, sample size, the disease stage of patients, the median and the range of following-up time, number of patients with positive $H$. pylori status, methods for $H$. pylori detection, the estimated HRs and their corresponding 95\% CIs for the OS, cancer specific mortality, DFS or relapse-free survival of the gastric cancer patients, and whether the risk estimate was adjusted for covariates.

\section{Eligibility study quality assessment}

For the eligible cohort studies, the quality assessment was performed with the modified NewcastleOttawa quality assessment scale [65]. A total of ten points was designated according to three broad perspectives, including the selection of the study groups (five points), 
the comparability of the groups (two points), and the ascertainment of either the exposure or outcome of interests for cohort studies respectively (three points). In the study selection category, five points were awarded if the study were performed with clearly diagnosed as gastric cancer (one point), compared the outcomes for H.pylori positive $v s$. negative status (one point), H.pylori status detected at the diagnosis (one point), and provided the diagnosis method ( 0 point for not reported, 1 point for single detection method and 2 points for studies with two or more detection methods). In the comparability category, a maximum 2 points were awarded if the risk estimate has been adjusted for the covariates of the patients. 0 point was awarded for those studies with the risk estimate was calculated based on the provided information, while 1 point was awarded for study provided the univariate risk estimate. For the outcome category, three points were awarded if the study concerned the OS or the DFS of the patients, with median following-up time more than 36 months and with sufficient following-up rate (Supplementary Table 1). Studies with total score $>7$ were recognized as with higher quality. Two authors (XF and KL) independently assessed the study quality and disagreements were resolved through discussing with the third author (PC).

\section{Statistical methods for meta-analysis studies}

The estimated HRs with their corresponding 95\% CIs for the $H$. pylori-positive in contrast to $H$. pylorinegative status were used to calculate the pooled hazard ratio estimates for OS or DFS of the gastric cancer patients. For those studies only provided a KaplanMeier plot of the gastric cancer patients outcomes that stratified by the $H$. pylori status, the survival curve was reconstructed with Engauge Digitizer software (version 4.1, GitHub, Inc.), and the plot was used to calculate the estimated HR and its 95\% CI, according to the method proposed by Tierney et al. [66]. For the other studies that provided the HR point estimate, the group size and the observed events or the log-rank statistic results for Kaplan-Meier plot, the HR estimate and its 95\% CI were calculated following the methods provided by Tierney et al. [66]. Estimates for relapse-free survival and cancerspecific survival were assumed to be the DFS and the OS in the current study, respectively.

In the meta-analysis, to establish appropriate weighting for each study, the SE for each logarithm HR $(\log \mathrm{HR})$ was calculated and recognized as the estimated variance for the $\log \mathrm{HR}$. The generic inverse variance approach was applied for weighting for each individual study. The DerSimonian and Laird random-effects model, which considers the variability both within and between studies, was applied to calculate the pooled estimate and its $95 \%$ confidential interval (95\% CI) [67]. Statistical heterogeneity between the studies was quantified with the
Cochrane Q-test, together with $\mathrm{I}^{2}$ statistics (significance set at $I^{2}>25 \%$ ). We also applied a graphical method proposed by Baujat et al. to identify those studies that contribute mostly to the heterogeneity between the studies [68]. Meta-regression method in together with the stratification analysis was applied to determine whether the pooled estimates could be influenced by the study level characteristics. Publication bias was represented as funnel plots and further assessed by the Egger's linear test and Begg's rank correlation test [69]. Sensitivity studies were performed by excluding individual studies and calculated the pooled estimates for the left studies repeatedly to identify the individual studies that significantly affected the overall estimates. The cumulative meta-analyses were also performed to chronologically determine the stabilization of the pooled estimates under the randomeffects model.

For all statistical analysis, the P-value $<0.05$ were considered as statistically significant for two-sided test. R software (version 3.1.1, www.r-project.org) and Revman (version 5.0) were used for all statistical analyses. The systematic review was performed and reported following the MOOSE guidelines (Supplementary Table 2).

\section{Author contributions}

Peizhan Chen and Fei Yuan conceived the idea and designed the study; Xuqian Fang, Kun Liu: performed the literature search, assessed the data quality and conducted the data analyses; Jialin Cai and Fangxiu Luo checked the studies and extracted the data; All authors contributed to manuscript writing and approved the final manuscript.

\section{ACKNOWLEDGMENTS}

None.

\section{CONFLICTS OF INTEREST}

The authors have no conflicts of interest to declare.

\section{FINANCIAL SUPPORT}

The work was financially supported by grants from the Science and Technology Commission of Shanghai Municipality (14391901800), and the Shanghai Municipal Commission of Health and Family Planning (20164Y0250). The funders had no role in study design, data collection and analysis, decision to publish, or preparation of the manuscript.

\section{REFERENCES}

1. Ferlay J, Soerjomataram I, Dikshit R, Eser S, Mathers C, Rebelo M, Parkin DM, Forman D, Bray F. Cancer 
incidence and mortality worldwide: sources, methods and major patterns in GLOBOCAN 2012. Int J Cancer. 2015; 136:E359-386.

2. Torre LA, Bray F, Siegel RL, Ferlay J, Lortet-Tieulent J, Jemal A. Global cancer statistics, 2012. CA Cancer J Clin. 2015; 65:87-108.

3. D'Angelica M, Gonen M, Brennan MF, Turnbull AD, Bains M, Karpeh MS. Patterns of initial recurrence in completely resected gastric adenocarcinoma. Ann Surg. 2004; 240:808816.

4. Kattan MW, Karpeh MS, Mazumdar M, Brennan MF. Postoperative nomogram for disease-specific survival after an R0 resection for gastric carcinoma. J Clin Oncol. 2003; 21:3647-3650.

5. Marshall BJ, Warren JR. Unidentified curved bacilli in the stomach of patients with gastritis and peptic ulceration. Lancet. 1984; 1:1311-1315.

6. Plummer M, Franceschi S, Vignat J, Forman D, de Martel C. Global burden of gastric cancer attributable to Helicobacter pylori. Int J Cancer. 2015; 136:487-490.

7. Ford AC, Forman D, Hunt RH, Yuan Y, Moayyedi P. Helicobacter pylori eradication therapy to prevent gastric cancer in healthy asymptomatic infected individuals: systematic review and meta-analysis of randomised controlled trials. BMJ. 2014; 348:g3174.

8. Marrelli D, Pedrazzani C, Berardi A, Corso G, Neri A, Garosi L, Vindigni C, Santucci A, Figura N, Roviello F. Negative Helicobacter pylori status is associated with poor prognosis in patients with gastric cancer. Cancer. 2009; 115:2071-2080.

9. Meimarakis G, Winter H, Assmann I, Kopp R, Lehn N, Kist M, Stolte M, Jauch KW, Hatz RA. Helicobacter pylori as a prognostic indicator after curative resection of gastric carcinoma: a prospective study. Lancet Oncol. 2006; 7:211222.

10. Wang F, Sun GP, Zou YF, Zhong F, Ma T, Li XQ, Wu D. Helicobacter pylori infection predicts favorable outcome in patients with gastric cancer. Curr Oncol. 2013; 20:e388395.

11. Fang N, Zhang HQ, He B, Xie M, Lu S, Wan YY, Wang NR. Clinicopathological characteristics and prognosis of gastric cancer with malignant ascites. Tumour Biol. 2014; 35:3261-3268.

12. Li G, Wang Z, Wang Z, Xu J, Cui J, Cai S, Zhan W, He Y. Gastric cancer patients with Helicobacter pylori infection have a poor prognosis. J Surg Oncol. 2013; 108:421-426.

13. Ling ZQ, Guo W, Lu XX, Zhu X, Hong LL, Wang Z, Wang $\mathrm{Z}$, Chen Y. A Golgi-specific protein PAQR3 is closely associated with the progression, metastasis and prognosis of human gastric cancers. Ann Oncol. 2014; 25:1363-1372.

14. Chen HY, Zhu BH, Zhang CH, Yang DJ, Peng JJ, Chen JH, Liu FK, He YL. High CpG island methylator phenotype is associated with lymph node metastasis and prognosis in gastric cancer. Cancer Sci. 2012; 103:73-79.
15. Chen WM, Wu CS, Liu JL, Yeh CM, Tseng L, Huang HC, Chang PJ, Wu SF. Expression of Helios in gastric tumor cells predicts better survival in gastric cancer patients. $\mathrm{J}$ Cancer Res Clin Oncol. 2016; 142:2375-2382.

16. Choi IK, Sung HJ, Lee JH, Kim JS, Seo JH. The relationship between Helicobacter pylori infection and the effects of chemotherapy in patients with advanced or metastatic gastric cancer. Cancer Chemother Pharmacol. 2012; 70:555-558.

17. Garcia-Gonzalez MA, Bujanda L, Quintero E, Santolaria S, Benito R, Strunk M, Sopena F, Thomson C, Perez-Aisa A, Nicolas-Perez D, Hijona E, Carrera-Lasfuentes P, Piazuelo E, et al. Association of PSCA rs2294008 gene variants with poor prognosis and increased susceptibility to gastric cancer and decreased risk of duodenal ulcer disease. Int J Cancer. 2015; 137:1362-1373.

18. Gong EJ, Ahn JY, Jung HY, Lim H, Choi KS, Lee JH, Kim DH, Choi KD, Song HJ, Lee GH, Kim JH, Choi SY, Choe JW, et al. Risk factors and clinical outcomes of gastric cancer identified by screening endoscopy: a case-control study. J Gastroenterol Hepatol. 2014; 29:301-309.

19. Hur H, Lee SR, Xuan Y, Kim YB, Lim YA, Cho YK, Han SU. The Effects of Helicobacter pylori on the prognosis of patients with curatively resected gastric cancers in a population with high infection rate. J Korean Surg Soc. 2012; 83:203-211.

20. Kang SY, Han JH, Ahn MS, Lee HW, Jeong SH, Park JS, Cho YK, Han SU, Kim YB, Kim JH, Sheen SS, Lim HY, Choi JH. Helicobacter pylori infection as an independent prognostic factor for locally advanced gastric cancer patients treated with adjuvant chemotherapy after curative resection. Int J Cancer. 2012; 130:948-958.

21. Kim HJ, Hwang SW, Kim N, Yoon H, Shin CM, Park YS, Lee DH, Park DJ, Kim HH, Kim JS, Jung HC, Lee HS. Helicobacter pylori and Molecular Markers as Prognostic Indicators for Gastric Cancer in Korea. J Cancer Prev. 2014; 19:56-67.

22. Kurtenkov O, Klaamas K, Sergeyev B, Chuzmarov V, Miljukhina L, Shljapnikova L. Better survival of Helicobacter pylori infected patients with early gastric cancer is related to a higher level of Thomsen-Friedenreich antigen-specific antibodies. Immunol Invest. 2003; 32:8393.

23. Lee WJ, Lin JT, Shun CT, Lee WC, Yu SC, Lee PH, Chang KJ, Wei TC, Chen KM. Comparison between resectable gastric adenocarcinomas seropositive and seronegative for Helicobacter pylori. Br J Surg. 1995; 82:802-805.

24. Lian G, Wei C, Wang D, Cui M, Wang Z, Liu X, Li W, Wang L, Wang Q, Zhang DY, Suo J, Ye F. Protein profiling of Helicobacter pylori-associated gastric cancer. Am J Pathol. 2014; 184:1343-1354.

25. Liu Y, Zhang Y, Zhao Y, Gao D, Xing J, Liu H. High PARP-1 expression is associated with tumor invasion and poor prognosis in gastric cancer. Oncol Lett. 2016; 12:38253835 . 
26. Piao Y, Li Y, Xu Q, Liu JW, Xing CZ, Xie XD, Yuan Y. Association of MTOR and AKT Gene Polymorphisms with Susceptibility and Survival of Gastric Cancer. PLoS One. 2015; 10:e136447.

27. Posteraro B, Persiani R, Dall'Armi V, Biondi A, Arzani D, Sicoli F, Bonassi S, D’Ugo D, Ricciardi W, Boccia S. Prognostic factors and outcomes in Italian patients undergoing curative gastric cancer surgery. Eur J Surg Oncol. 2014; 40:345-351.

28. Postlewait LM, Squires MH, Kooby DA, Poultsides GA, Weber SM, Bloomston M, Fields RC, Pawlik TM, Votanopoulos KI, Schmidt CR, Ejaz A, Acher AW, Worhunsky DJ, et al. Preoperative Helicobacter pylori Infection is Associated with Increased Survival After Resection of Gastric Adenocarcinoma. Ann Surg Oncol. 2016; 23:1225-1233.

29. Qiu HB, Zhang LY, Keshari RP, Wang GQ, Zhou ZW, Xu DZ, Wang W, Zhan YQ, Li W. Relationship between H.Pylori infection and clinicopathological features and prognosis of gastric cancer. BMC Cancer. 2010; 10:374.

30. Roberts PO, Plummer J, Leake PA, Scott S, de Souza TG, Johnson A, Gibson TN, Hanchard B, Reid M. Pathological factors affecting gastric adenocarcinoma survival in a Caribbean population from 2000-2010. World J Gastrointest Surg. 2014; 6:94-100.

31. Santos RS, Lourenco JE, Herbella FA, Del Grande JC, Patti MG. Helicobacter pylori has no influence on distal gastric cancer survival. Arq Gastroenterol. 2011; 48:109-111.

32. Shen J, Xiao Z, Wu WK, Wang MH, To KF, Chen Y, Yang W, Li MS, Shin VY, Tong JH, Kang W, Zhang L, Li M, et al. Epigenetic silencing of miR-490-3p reactivates the chromatin remodeler SMARCD1 to promote Helicobacter pylori-induced gastric carcinogenesis. Cancer Res. 2015; 75:754-765.

33. Syrios J, Sougioultzis S, Xynos ID, Kavantzas N, Kosmas C, Agrogiannis G, Griniatsos J, Karavokyros I, Pikoulis E, Patsouris ES, Tsavaris N. Survival in patients with stage IV noncardia gastric cancer-the influence of DNA ploidy and Helicobacter pylori infection. BMC Cancer. 2012; 12:264.

34. Tsai KF, Liou JM, Chen MJ, Chen CC, Kuo SH, Lai IR, Yeh KH, Lin MT, Wang HP, Cheng AL, Lin JT, Shun CT, Wu MS, et al. Distinct Clinicopathological Features and Prognosis of Helicobacter pylori Negative Gastric Cancer. PLoS One. 2017; 12:e0170942.

35. Wang G, Zhang W, Zhou B, Jin C, Wang Z, Yang Y, Wang Z, Chen Y, Feng X. The diagnosis value of promoter methylation of UCHL1 in the serum for progression of gastric cancer. Biomed Res Int. 2015; 2015:741030.

36. Wei B, Shi H, Lu X, Shi A, Cheng Y, Dong L. Association between the expression of T-cadherin and vascular endothelial growth factor and the prognosis of patients with gastric cancer. Mol Med Rep. 2015; 12:2075-2081.

37. Zhang $\mathrm{C}, \mathrm{Yu} \mathrm{H}, \mathrm{Xu} \mathrm{H}$, Yang L. Expression of secreted phospholipase A2-Group IIA correlates with prognosis of gastric adenocarcinoma. Oncol Lett. 2015; 10:3050-3058.

38. Zhao W, Zhu H, Zhang S, Yong H, Wang W, Zhou Y, Wang B, Wen J, Qiu Z, Ding G, Feng Z, Zhu J. Trop2 is overexpressed in gastric cancer and predicts poor prognosis. Oncotarget. 2016; 7:6136-6145. https://doi.org/10.18632/ oncotarget.6733.

39. Zhou F, Shi J, Fang C, Zou X, Huang Q. Gastric Carcinomas in Young (Younger than 40 Years) Chinese Patients: Clinicopathology, Family History, and Postresection Survival. Medicine (Baltimore). 2016; 95:e2873.

40. Gan L, Zhang X, Pan J, Liu K, Li P, Wang X, Wang J. Helicobacter pylori infection status as a prognostic indicator for gastric cancer. Acad J Second Military Med Univ. 2011; 32:1300-1305.

41. Warren JR, Marshall B. Unidentified curved bacilli on gastric epithelium in active chronic gastritis. Lancet. 1983; 1:1273-1275.

42. Parsonnet J, Forman D. Helicobacter pylori infection and gastric cancer--for want of more outcomes. JAMA. 2004; 291: 244-245.

43. Graham DY. Helicobacter pylori infection is the primary cause of gastric cancer. J Gastroenterol. 2000; 35:90-97.

44. Wang C, Yuan Y, Hunt RH. Helicobacter pylori infection and Barrett's esophagus: a systematic review and metaanalysis. Am J Gastroenterol. 2009; 104:492-500.

45. Chen Y, Blaser MJ. Helicobacter pylori colonization is inversely associated with childhood asthma. J Infect Dis. 2008; 198:553-560.

46. Bamford KB, Fan X, Crowe SE, Leary JF, Gourley WK, Luthra GK, Brooks EG, Graham DY, Reyes VE, Ernst PB. Lymphocytes in the human gastric mucosa during Helicobacter pylori have a $\mathrm{T}$ helper cell 1 phenotype. Gastroenterology. 1998; 114:482-492.

47. Fridman WH, Pages F, Sautes-Fridman C, Galon J. The immune contexture in human tumours: impact on clinical outcome. Nat Rev Cancer. 2012; 12:298-306.

48. Zhuang Y, Shi Y, Liu XF, Zhang JY, Liu T, Fan X, Luo J, Wu C, Yu S, Chen L, Luo P, Guo G, Liu Z, et al. Helicobacter pylori-infected macrophages induce Th17 cell differentiation. Immunobiology. 2011; 216:200-207.

49. Evans DJ, Evans DG, Takemura T, Nakano H, Lampert HC, Graham DY, Granger DN, Kvietys PR. Characterization of a Helicobacter pylori neutrophil-activating protein. Infect Immun. 1995; 63:2213-2220.

50. Amedei A, Cappon A, Codolo G, Cabrelle A, Polenghi A, Benagiano M, Tasca E, Azzurri A, D'Elios MM, Del Prete $\mathrm{G}$, de Bernard $\mathrm{M}$. The neutrophil-activating protein of Helicobacter pylori promotes Th1 immune responses. J Clin Invest. 2006; 116:1092-1101.

51. Codolo G, Fassan M, Munari F, Volpe A, Bassi P, Rugge M, Pagano F, D'Elios MM, de Bernard M. HP-NAP inhibits the growth of bladder cancer in mice by activating a cytotoxic Th1 response. Cancer Immunol Immunother. 2012; 61:31-40. 
52. Iankov ID, Allen C, Federspiel MJ, Myers RM, Peng $\mathrm{KW}$, Ingle JN, Russell SJ, Galanis E. Expression of immunomodulatory neutrophil-activating protein of Helicobacter pylori enhances the antitumor activity of oncolytic measles virus. Mol Ther. 2012; 20:1139-1147.

53. Ramachandran M, Yu D, Wanders A, Essand M, Eriksson F. An infection-enhanced oncolytic adenovirus secreting $\mathrm{H}$. pylori neutrophil-activating protein with therapeutic effects on neuroendocrine tumors. Mol Ther. 2013; 21:2008-2018.

54. Leung WK, Kim JJ, Kim JG, Graham DY, Sepulveda AR. Microsatellite instability in gastric intestinal metaplasia in patients with and without gastric cancer. Am J Pathol. 2000; 156:537-543.

55. Wu MS, Lee CW, Shun CT, Wang HP, Lee WJ, Sheu JC, Lin JT. Clinicopathological significance of altered loci of replication error and microsatellite instability-associated mutations in gastric cancer. Cancer Res. 1998; 58:14941497.

56. Wu MS, Lee CW, Sheu JC, Shun CT, Wang HP, Hong RL, Lee WJ, Lin JT. Alterations of BAT-26 identify a subset of gastric cancer with distinct clinicopathologic features and better postoperative prognosis. Hepatogastroenterology. 2002; 49:285-289.

57. Zhou X, Su J, Zhu L, Zhang G. Helicobacter pylori modulates cisplatin sensitivity in gastric cancer by downregulating miR-141 expression. Helicobacter. 2014; 19:174181.

58. Hobsley M, Tovey FI, Holton J. Helicobacter pylori and gastric cancer: neither friend nor foe. Gastroenterology. 2007; 132:2076.

59. Pacelli F, Papa V, Caprino P, Sgadari A, Bossola M, Doglietto GB. Proximal compared with distal gastric cancer: multivariate analysis of prognostic factors. Am Surg. 2001; 67:697-703.
60. Huang Q, Fang C, Shi J, Sun Q, Wu H, Gold JS, Weber HC, Guan W, Zhang Y, Yu C, Zou X, Mashimo H. Differences in Clinicopathology of Early Gastric Carcinoma between Proximal and Distal Location in 438 Chinese Patients. Sci Rep. 2015; 5:13439.

61. Wang F, Sun G, Zou Y, Zhong F, Ma T, Li X. Protective role of Helicobacter pylori infection in prognosis of gastric cancer: evidence from 2,454 patients with gastric cancer. PLoS One. 2013; 8:e62440.

62. Muller A. Multistep activation of the Helicobacter pylori effector CagA. J Clin Invest. 2012; 122:1192-1195.

63. Atherton JC, Blaser MJ. Coadaptation of Helicobacter pylori and humans: ancient history, modern implications. J Clin Invest. 2009; 119:2475-2487.

64. Israel DA, Salama N, Arnold CN, Moss SF, Ando T, Wirth HP, Tham KT, Camorlinga M, Blaser MJ, Falkow S, Peek RM. Helicobacter pylori strain-specific differences in genetic content, identified by microarray, influence host inflammatory responses. J Clin Invest. 2001; 107:611-620.

65. Stang A. Critical evaluation of the Newcastle-Ottawa scale for the assessment of the quality of nonrandomized studies in meta-analyses. Eur J Epidemiol. 2010; 25:603-605.

66. Tierney JF, Stewart LA, Ghersi D, Burdett S, Sydes MR. Practical methods for incorporating summary time-to-event data into meta-analysis. Trials. 2007; 8:16.

67. DerSimonian R, Laird N. Meta-analysis in clinical trials. Control Clin Trials. 1986; 7:177-188.

68. Baujat B, Mahe C, Pignon JP, Hill C. A graphical method for exploring heterogeneity in meta-analyses: application to a meta-analysis of 65 trials. Stat Med. 2002; 21:2641-2652.

69. Egger M, Davey Smith G, Schneider M, Minder C. Bias in meta-analysis detected by a simple, graphical test. BMJ. 1997; 315:629-634. 